\section{Response to the letter sent by Dr. Viroj Wiwanitkit entitled "Body mass index and screening for cardiovascular disease risk"}

\author{
Resposta à carta enviada pelo Dr. Viroj Wiwanitkit, intitulada "Índice \\ de massa corporal e avaliação do risco de doença cardiovascular"
}

Gabriel Gustavo Bergmann', Mauren Lúcia de Araújo

Bergmann², Ricardo Rodrigo Rech ${ }^{3}$, Cristine Boone Constanzi², Lidiane Requia Alli2 ${ }^{2}$, Ricardo Halpern², Adroaldo Gaya ${ }^{4}$

$\mathrm{F}$ irst I want to express our satisfaction, as the authors of the article "Body Mass InDex to the Cardiovascular Risk Factors Screening in Infancy" published in March, 2011 in the Brazilian Archives of Endocrinology and Metabolism (2011;55(2):11420 ), to know that the manuscript have been accessed and used as an element of reflection by renowned researchers such as Dr. Wiwanitkit. However, the reason why we send this letter is to discuss the issues raised and the suggestions made by Dr. Wiwanitkit in his letter to the editor commenting our article.

The first point refers to the term "infancy", whose use in the title of the article was questioned by Dr. Wiwanitkit, considering that the study was conducted with individuals from 7 to 12 years of age. Infancy is the period of life that ranges from conception to about 12 years old, and it is divided in first infancy (birth to 2 years old), second infancy ( 2 to 6 years old) and late infancy ( 6 to 12 years old) (1). Thus, we consider that, although the term encompasses more than the ages 7 to 12 , these ages are within the period of life called infancy.

Although the second and third points raised by Dr. Wiwanitkit are extremely relevant, we believe they set us away for the objective of the study. Thus, these two questions will be answered together. The authors, as Dr. Wiwanitkit, are aware of the information available in literature indicating that the body mass index (BMI) is mediated by different elements including feeding habits, and that excess weight is influenced by different risk factors, including sleep habits (2).

However, the intention of the article was to provide BMI cutoff values obtained from cardiovascular risk factor references, rather than carry out a study on associated factors of excess weight, although this kind of study is essential, as evidenced by Must and cols. (2). Therefore, our objective was to provide an empirically validated instrument for the screening of school children and adolescents with increased probability of presenting cardiovascular risk factors, to professionals who work with this age group. In order to reach this objective, we used information about blood pressure (systolic and diastolic) and total cholesterol. These factors were chosen to compose the cardiovascular risk factor reference because, together with smoking and diabetes mellitus, they are the main modifiable cardiovascular risk factors (3).

\section{REFERENCES}

1. Gabbard C. Lifelong motor development (5th ed.). San Francisco, CA: Benjamin Cumming; 2008.

2. Must $A$, Barish EE, Bandini LG. Modificable risk factors in relation to changes in $B M I$ and fatness: what have we larned from prospective studies of school-aged children? Int J Obes. 2009;33(7):705-15.

3. Canto JG, Iskandrian AE. Major risk factors for cardiovascular disease. JAMA. 2003;290(7):947-9.
1 Universidade Federal do Pampa (Unipampa), Uruguaiana, RS, Brazil 2 Universidade Luterana do Brasil (Ulbra), Canoas, RS, Brasil ${ }^{3}$ Universidade de Caxias do Sul (UCS), Caxias do Sul, RS, Brasil 4 Universidade Federal do Rio Grande do Sul, Porto Alegre, RS, Brasil

\section{Correspondence to:} Gabriel Gustavo Bergmann Universidade Federal do Pampa, Campus Uruguaiana (Unipampa) BR 472, km 592,

Caixa postal 118, Uruguaiana, RS, Brazil

97500-970

gabrielgbergmann@gmail.com

Received on Jul/8/2011 Accepted on Aug/4/2011 